\title{
OBSTÁCULOS AL RECONOCIMIENTO CONSTITUCIONAL DE LOS PUEBLOS Y COMUNIDADES AFROMEXICANAS: ¿OBJECIONES DEL RACISMO?
}

\author{
Obstacles to the Constitutional Recognition of Afromexican Peoples \\ and Communities: Racist Objections?
}

\section{GABRIELA ITURRALDE*}

Fecha de recepción: 16 de agosto de 2017 - Fecha de aprobación: 13 de noviembre de 2017

\section{Resumen}

En este texto se reflexiona en torno de las formas de expresión del racismo hacia las personas afrodescendientes en México: invisibilización, extranjerización e hipervisibilización y la relación de estas ideas y prácticas con los obstáculos que hasta ahora ha enfrentado la demanda de reconocimiento constitucional. Las reflexiones que se ofrecen resultan del dialogo disciplinario entre la historia y la antropología. Por una parte, hay una aproximación desde los estudios historiográficos para documentar el desarrollo de estereotipos e ideas de corte racista hacia las personas afrodescendientes en el siglo XIX en México. Por otra, se ha realizado un trabajo permanente de observación participativa y registro de las acciones colectivas afromexicanas que se desarrollan tanto en las regiones en donde se encuentran asentadas la mayoría de las organizaciones sociales afromexicanas (Costa Chica de Guerrero y Oaxaca) como en sus interacciones con las instituciones gubernamentales y otros ámbitos de gestión política. Las objeciones que se esgrimen en contra del reconocimiento constitucional de los pueblos y comunidades afromexicanas son consistentes con algunos de los elementos que históricamente caracterizan las expresiones del racismo hacia las personas afromexicanas.

Palabras clave: Multiculturalidad, reconocimiento jurídico, afromexicanos, invisibilización

\section{Abstract}

The aim of this paper is to reflect about the characteristics of racism towards Afromexican people: and the relationship between racist ideas and practices with the obstacles that have so far faced the demand for constitutional recognition. The reflections offered result from the disciplinary dialogue between history and anthropology, from historiographical studies to document the development of racist stereotypes and ideas towards Afro-descendants in the 19th century in Mexico and also as a result of fieldwork and ethnographic registration of the Afromexican collective actions. The objections raised against the constitutional recognition of Afromexican peoples and communities are consistent with some of the elements that historically characterize the expressions of racism toward people of African descent in México.

Keywords: Multiculturalism, racism, afromexicans, legal recognition

* Mtra. en Antropología Social. Investigadora del Programa Nacional de Investigación Afrodescendientes y Diversidad Cultural, Coordinación Nacional de Antropología, Instituto Nacional de Antropología e Historia (INAH), Ciudad de México, México. El artículo está enmarcado en un proyecto interno de la institución de afiliación. Correo-e: giturraldenieto@gmail.com 


\section{Introducción}

A raíz de la declaración del año 2011, como año Internacional de las Personas Afrodescendientes en México, las acciones reivindicativas de las organizaciones y comunidades afromexicanas han adquirido mayor visibilidad. Ubicadas principalmente en la región de la Costa Chica de Guerrero y Oaxaca, asociaciones, cooperativas y otras formas de organización se han articulado en un movimiento político que con sus reclamos y acciones - muchas de las veces calificadas de poco visibles y efectivashan puesto en cuestión la idea de que la pluriculturalidad de la nación mexicana recae solamente en los pueblos y comunidades indígenas - tal como lo señala la Constitución Política de los Estados Unidos Mexicanos (CPEUM) en su artículo segundo-, y han obligado al Estado a volver la mirada sobre esta otra alteridad social presente en México desde tiempos virreinales y negada a partir del inicio de la vida republicana.

En los últimos años el movimiento afromexicano o mas precisamente sus acciones colectivas, han estado encaminadas a poner en la escena pública su derecho a ser reconocidos jurídicamente. Le reclaman al Estado ser incluidos en la Constitución y la garantía de un conjunto de derechos en razón de su condición de colectividad históricamente excluida de la nación (Velázquez \& Iturralde, 2016). Asimismo, en la actualidad existe un renovado interés científico y social por caracterizar el racismo - fenómeno cuya existencia en México había sido sistemáticamente negada o cuando menos minimizada - y que actualmente incluso las instituciones del Estado reconocen su condición estructurante de la desigualdad social ${ }^{1}$.
Así pues, la emergencia del movimiento afromexicano como actor político ha llamado la atención sobre la necesidad de caracterizar las expresiones del racismo hacia la población afrodescendiente que, como he dicho párrafos anteriores, es una colectividad "borrada" del relato nacional, estigmatizada como inferior y que enfrenta sistemáticamente expresiones de racismo que han sido naturalizadas. Indagar en las manifestaciones específicas del racismo hacia la población afromexicana puede arrojar algunas pistas sobre estos procesos en México, fenómeno que se expresa de manera sutil, soterrada o encubierta.

En este texto me propongo reflexionar en torno de las formas de expresión del racismo hacia las personas afrodescendientes en México y la relación de estas ideas y prácticas con los obstáculos que hasta ahora ha enfrentado la demanda de reconocimiento constitucional por parte de estas colectividades, no sólo en el ámbito de las instituciones del Estado sino también de la vida cotidiana, pues considero que las objeciones en contra del reconocimiento constitucional de los pueblos y comunidades afromexicanas, esgrimidas en distintos ámbitos, son consistentes con los aspectos que parecen caracterizar las expresiones del racismo hacia las personas afromexicanas.

Para ello inicialmente me refiero brevemente a los estudios sobre racismo en México, en ese marco me interesa detenerme en aquellos enfocados hacia la documentación y análisis del racismo hacia las personas afrodescendientes. Posteriormente abordo cuales son los elementos que caracterizan las expresiones del racismo hacia las personas "negras" o afrodescendientes en México. Finalmente expongo por qué considero que la dilación en el reconocimiento constitucio- 
nal hacia este grupo de población se debe más a la reproducción de las consideraciones "racistas" hacia este grupo de población y no únicamente al descuido o inercias propias del trabajo de legisladores y otros tomadores de decisiones.

Las reflexiones que aquí ofrezco resultan del imprescindible diálogo disciplinario entre la historia y la antropología. Por una parte, me he aproximado desde los estudios historiográficos para documentar el desarrollo de estereotipos e ideas de corte racista hacia las personas afrodescendientes en el siglo XIX en México. También, he realizado trabajo permanente de observación participativa y documentación de las acciones colectivas afromexicanas que se desarrollan tanto en las regiones en donde se encuentran asentadas la mayoría de las organizaciones sociales afromexicanas (Costa Chica de Guerrero y Oaxaca) como en sus interacciones con las instituciones gubernamentales y otros ámbitos de gestión política. Y finalmente, incluyo algunas reflexiones derivadas de los primeros hallazgos de un proyecto de investigación etnográfica en curso, basada en la recuperación de relatos de prácticas sobre trayectorias políticas de mujeres de la Costa Chica y sus estrategias cotidianas para enfrentar el racismo.

Cabe señalar que el estudio del racismo hacia las poblaciones afrodescendientes o cualquier otra colectividad, requiere de desarrollar herramientas que permitan comprender, por una parte los procesos del racismo en sus expresiones doctrinarias e ideológicas presentes, por ejemplo, en el pensamiento político y en su nivel institucional, así como en el de la vida cotidiana a través de la documentación y análisis de las prácticas ya sean de las instituciones del Estado, en la escuela o en las interacciones cotidianas entre las personas.
El registro y análisis de esta última dimensión, es la que desde las perspectivas de la investigación antropológica, puede arrojar claves para comprender las lógicas de reproducción del racismo, fenómeno que parece mantener su capacidad estructurante de relaciones sociales jerarquizadas y excluyentes, y que a pesar de los esfuerzos que se realizan para su eliminación tiene una gran capacidad de resematización. Así pues, se requiere del concurso de miradas desde distintos ángulos disciplinares para abordar la complejidad del fenómeno e identificar, también, las posibilidades de enfrentamiento y acción en su contra.

\section{¿México racista?}

Entiendo que el racismo es al mismo tiempo una teoría, una doctrina política, un sistema de pensamiento y un conjunto de prácticas que consideran que la diversidad de los grupos humanos -variabilidad física visible, la cultura, las características morales- es atribuible a la existencia de distintas "razas" entre los humanos y que establece un sistema de jerarquización social en función de la valoración como superiores e inferiores de esas características. Tal como lo señala P. A. Taguieff (2010, p. 28), "[el racismo] se refiere hoy a actitudes (opiniones, creencias, prejuicios, estereotipos), comportamientos o prácticas sociales (apartar, discriminar, segregar, perseguir, etc.), funcionamientos institucionales de tipo exclusionista, y a construcciones ideológicas que se presentan como doctrinas o teorías" y que estas se materializan en los niveles macro y micro social, es decir en las instituciones sociales, los comportamientos del aparato del Estado y también en las interacciones cotidianas de los colectivos y los individuos. 
Desde esta perspectiva, la pregunta sobre si México es racista, parece recibir un sí contundente. En años recientes han aumentado las investigaciones realizadas desde disciplinas como la historia, la sociología y la antropología que se han ocupado de argumentar en contra de la idea generalizada de que México, al ser desde su fundación una nación mestiza, se habría librado de las prácticas del racismo. Dedicadas a indagar en los procesos de conformación de los discursos y las prácticas de la raza y el racismo, estas investigaciones han puesto en cuestión la construcción ideológica del mestizaje como doctrina de la identidad nacional y empiezan a evidenciar el complejo tejido en el que se articula el racismo en México.

Federico Navarrete (2016) ha propuesto en un trabajo reciente las que él considera las tesis centrales para la comprensión del racismo en México y los efectos estructurantes de este pensamiento y prácticas sobre fenómenos sociales contemporáneos, como la violencia hacia los pueblos y comunidades indígenas $u$ otras colectividades, misma que ha llegado a niveles paroxísticos con la desaparición de 43 estudiantes de la normal rural de Ayotzinapa en 2014.

Antes del trabajo arriba mencionado, distintos autores han indagado en esta materia, por ejemplo, la historia intelectual se ha enfocado en documentar y reflexionar acerca de la influencia que tuvieron las ideas del racismo científico decimonónico en la formación del discurso nacional sobre el mestizaje y analizar el imaginario de algunos de los principales pensadores del siglo XIX acerca de la "diversidad racial" existente en el país. El pensamiento de Pimentel, Raigosa, Bulnes, Mora, Sierra dedicado a pensar la manera de solucionar "los problemas nacionales" con miras a construir una nación moderna y de progreso han sido profusamente estudiados como fuentes para comprender la construcción del mestizo como el sujeto histórico nacional y a la vez la construcción del indígena como la alteridad social que debía redimirse (Jiménez, 2004). Textos como este dan cuenta de la fuerte impronta de las ideas sobre las razas en el desarrollo no solo intelectual sino también en el pensamiento político mexicano.

El período posrevolucionario, la consolidación del proyecto nacional basado en la idea del mestizaje y la circulación de las ideas eugenésicas como políticas de estado en este período, han sido también motivo de atención científica. El surgimiento de la ideología nacionalista y el papel que en este tiene la idea del mestizo como encarnación del sujeto nacional mexicano se analizan en Lomnitz (1995), Knight (2004), entre otros. Destacan los trabajos de Beatriz Urías Horcasitas (2007), en su argumentación llama la atención su afirmación acerca de que la propuesta de la élite política e intelectual triunfante en la revolución de transformar la sociedad mexicana mediante la 'depuración racial' constituyó un planteamiento utópico inviable e irreal que no obstante esto estuvo en el origen de hechos reales: la política indigenista de 'unidad racial', la explicación de la criminalidad como atributo de algunos individuos y grupos étnicos, la promoción de la inmigración "blanca", por citar solo algunos. En esta medida, existe una línea de continuidad entre los postulados acerca de las razas que aparecieron a lo largo del siglo XIX y aquellos que articularon la ideología posrevolucionaria y que han perdurado de manera invisible en la sociedad mexicana. 
Otra vertiente de los trabajos sobre racismo se refiere a las condiciones de injusticia e inequidad de la que son objeto los pueblos indígenas, puestos en evidencia al gran público a raíz del levantamiento del EZLN en 1994. Esto ha dado trabajos que desde distintas perspectivas abordan las relaciones interétnicas, Olivia Gall (2007, 2014) y Alicia Castellanos (2003, 2001, 2000) han atendido esta temática poniendo especial atención en las relaciones entre indígenas y "ladinos" en las comunidades de los altos de Chiapas. Castellanos es sin duda la más prolífica autora sobre la temática y se ha preocupado también en reflexionar acerca de las posiciones que la antropología mexicana y los profesionales de esta disciplina han desarrollado respecto de la raza, el racismo y la discriminación racial. Destaca el papel que éstos han desempeñado en relación con la formación primero de la ideología del mestizaje y luego de la política indigenista, entendidas estas dos como las fuentes de las que se nutren las políticas de comprensión y gestión de la alteridad desde el Estado mexicano.

José J. Gómez Izquierdo (2005, 1991) ha atendido los sucesos racistas en contra de trabajadores chinos que tuvieron lugar en el norte de México a finales del siglo XIX y el primer cuarto del siglo $X X$ y que culminaron con la expulsión masiva de trabajadores chinos en el período de la presidencia de Plutarco Elías Calles. Recientemente se han realizado algunos otros trabajos que exploran elementos de la construcción nacional mexicana a partir de la creación de estigmas xenófobos alrededor de la población de origen chino, ahondando en la relación "raza" - nación como mancuerna sobre la que se elaboran los procesos del racismo (Campos, 2009).
El estudio de las expresiones del racismo en las diferentes regiones de México empieza a ser importante, destaca entre estos trabajos el de Eugenia Iturriaga (2016) quien analiza con gran precisión etnográfica las prácticas racistas de la élite yucateca. La autora atiende los rituales cotidianos a través de los cuales esta élite elabora la violencia material y simbólica hacia los pueblos mayas peninsulares, basada en una idea de superioridad "racial". Este trabajo arroja pistas útiles para comprender cómo las prácticas racistas han sido normalizadas como códigos de comportamiento correctos y requisitos de pertenencia al grupo dominante. Además, pone en evidencia la relación existente entre los procesos del racismo y la conformación de la dominación social y económica en la región.

Mónica Moreno Figueroa (2010, 2008a, 2008b) es otra autora cuyo interés es poner en evidencia el racismo en México. Su trabajo se inscribe dentro de una línea poco explorada en América Latina, la de los estudios sobre blanquedad (whiteness) que conciben a la 'blanquedad' como una posición social de privilegio más que el hecho de ser blanco. La autora encuentra en esta corriente algunos aspectos útiles para explicar cómo algunas mujeres que se reconocen como mestizas y no se asumen pertenecientes a un grupo etnizado/racializado, viven y sienten el racismo.

El mestizaje es para la autora un espacio de blanquedad al que se aspira y se accede de manera fragmentada y contradictoria según los contextos y las relaciones en las que se construyen y desarrollan las interacciones. La autora presenta un enfoque novedoso en el contexto mexicano y aporta una dimensión que complejiza la experimentación de las identidades racializadas. Asimismo se han desarrollado algunas 
aproximaciones, sobre todo desde la sociología empírica, enfocadas a explorar los procesos del racismo y la desigualdad, centradas en el colorismo, intentando aplicar para el caso de México explicaciones desarrolladas para contextos como el brasileño o el norteamericano en los que parece ser que las ideas sobre la raza y los desarrollos identitarios tienen fuertes anclajes en el colorismo y la pigmentación de la piel (Tellez, 2014). El texto arroja datos interesantes sobre los procesos de categorización identitaria y abre interrogantes cuya atención es imprescindible para profundizar en las caracterizaciones del racismo en México.

\section{Estudiar el racismo hacia los afrodescen- dientes en México}

Poco se ha estudiado sobre el racismo hacia las poblaciones afrodescendientes en México, en el marco del auge de los estudios sobre afromexicanística, Catharine Good (1998) anticipa algunos de los problemas teóricos y metodológicos que enfrentan los estudiosos sobre la historia y la vida contemporánea de la población afrodescendiente en México. La autora explora los problemas analíticos que abordan una serie de estudios etnohistóricos y antropológicos acerca de grupos afroamericanos publicados en el extranjero sobre regiones como el Caribe, América Latina y los Estados Unidos.

En este acercamiento se pregunta -teniendo en cuenta la particularidad mexicana- qué se puede aprender de la amplia documentación referente a otras regiones para avanzar en los estudios históricos y antropológicos sobre México, considerando que es imposible hacer investigación acerca de la población de origen africano y sus descendientes sin estudiar los complejos temas del racismo, la etnicidad, la estratificación social, el colonialismo y el nacionalismo.

¿Existe el racismo sin razas? se pregunta la autora, una vez constatado el hecho de que las razas existen solo como una construcción social derivada de pensamiento racialista y racista del siglo XIX, para Good es imprescindible atender cómo se produce esta construcción y cómo se experimenta cotidianamente. Apunta también un imponderable para los estudios sobre la historia y el presente de las poblaciones afrolatinoamericanas; tener en cuenta la distinta comprensión de la noción de raza de acuerdo a los contextos intelectuales y académicos en los que se producen las investigaciones o de quienes las producen.

En el campo de los estudios sobre la diáspora africana han dominado las escuelas de interpretación norteamericanas, para muchas de ellas la noción de raza no ha perdido vigencia como categoría descriptiva de una supuesta realidad biológica, realidad distinta de las latinoamericanas y en especial de la mexicana en donde es casi indiscutible la idea de la raza como construcción social, donde la pertinencia de su uso, incluso como categoría analítica, con frecuencia es puesta en cuestión. En este sentido se debe destacar que buena parte de los trabajos realizados por académicos norteamericanos, que buscaron documentar la historia de la población afromexicana, se centraron en una perspectiva que desarrolla una comprensión de la experiencia afrodescendiente en México considerando a este grupo social como una "raza" en un sentido preminentemente biológico, partiendo de la idea de que en efecto las razas existen y que las dinámicas de inclusión / exclusión o alterización / identificación del pasado colonial 
estuvieron marcadas por una supuesta pertenencia a un grupo racial (Palmer, 1976; Mc Caa \& Schwartz, 1979; Stern, 1994; Vinson III, 2001; Carroll 2001). A este debate se refiere Patrick Carroll (2011).

Años más tarde, Marta M. Saade (2009) en un interesante artículo, a partir de un minucioso trabajo de revisión de los archivos del Instituto Nacional de Migración, da cuenta del desarrollo de las políticas inmigratorias mexicanas a partir de la segunda mitad del siglo XIX y su marcado carácter racialista que restringió, cuando no impidió, el arribo y asentamiento de personas y comunidades afrodescendientes en México provenientes sobre todo de Estados Unidos, Honduras Británica (Belice) y Cuba. Haciendo uso de documentos sobre comunicaciones confidenciales entre autoridades políticas y agentes migratorios así como de cartas de extranjeros interesados en inmigrar, su trabajo pone en evidencia la preocupación del Estado mexicano por evitar la presencia de personas "negras", sobre todo en la primera etapa del período posrevolucionario. Escondida detrás de la obligación de protección de las fuentes de empleo para los mexicanos, la argumentación considera a los negros como miembros de una raza indeseable que no se adaptarían fácilmente a las características del mestizaje nacional.

Además de aportar datos hasta hace poco desconocidos, la autora da luces para comprender el lugar que ocuparon entonces y quizá aun ocupan los afrodescendientes en la construcción de la idea "del mexicano". En un sentido parecido Elisabeth Cunin (2014) estudia las migraciones afrobeliceñas a Quintana Roo -entidad del sudeste del país incorporado tardíamente a la nación-. La documentación de estos casos le es útil para reflexionar acerca del lugar del extranjero-negro en el mestizaje y sobre el establecimiento de políticas migratorias de corte racialista que buscan administrar "la raza", sin asegurar que se trata de la existencia de un sistema institucional racista antinegro. La autora identifica lo que considera el dominio de una ideología racializada que se aplica especialmente a los migrantes negros bajo la forma de la discriminación racial (Cunin, 2014). Cabe destacar también el trabajo realizado para el caso del Puerto de Veracruz por Christina Sue (2013), en el que indaga en los procesos identitarios entre los distintos grupos sociales de esta ciudad y el papel que juega el "color" de piel y "la raza" en la construcción del mestizaje, basando su análisis en las categorizaciones estigmatizadas del negro.

En los últimos tres años se han realizado importantes esfuerzos de investigación sobre el racismo hacia las poblaciones afrodescendientes en México, trabajos centrados sobre todo en la Costa Chica de Guerrero y Oaxaca han indagado en el papel que tienen las concepciones sobre la raza y los estereotipos racistas en las relaciones de sociabilidad y las relaciones interétnicas en la región (Correa, 2013; Masferrer, 2014, 2016; Quecha, 2016).

En torno de un proyecto de investigación llevado a cabo en el INAH se ha establecido un seminario de reflexión sobre esta temática, desde perspectivas etnohistóricas y antropológicas se ha buscado contribuir a la comprensión del desarrollo histórico del racismo hacia las poblaciones africanas y afrodescendientes en la Nueva España y el México decimonónico. De las investigaciones particulares involucradas en este proyecto y resultado de ejercicios de reflexión colectiva, se han desprendido algunos 
ejes analíticos en torno de los cuales se debe profundizar: el tránsito de las concepciones sobre las distinciones y el orden social entre los períodos formativos del período colonial y la época borbónica, la relación del auge del comercio de personas esclavizadas y el pensamiento racista.

Así mismo se ha hecho énfasis en las discusiones sobre abolición de la esclavitud y ciudadanía en el temprano siglo XIX, momento en el que es central la reflexión sobre el papel que juega la noción de raza como un dispositivo político para la construcción de las naciones y la inclusión-exclusión de unos u otros colectivos en el cuerpo nacional. También se han explorado fuentes -crónicas de viaje, relatos literarios, pinturas y fotografías- para identificar a lo largo del siglo XIX la creación y diseminación de estereotipos sobre las personas "negras" en México. Las aproximaciones etnográficas han permitido conocer y describir las distintas esferas de la praxis del racismo contemporáneo y las implicaciones que tienen en la vida de las personas afromexicanas.

\section{Caracterizando el racismo hacia los afrodescendientes}

México no es formalmente un país racista, no existen leyes ni ningún otro tipo de disposiciones jurídicas que impidan explícitamente el ejercicio de un derecho o el acceso a bienes y servicios en razón del color de piel, la fisonomía o la cultura de las personas o las colectividades, sin embargo la observación de la realidad social, tanto de las interacciones entre los individuos como ciertas prácticas del Estado a través del aparato de gobierno y sus instituciones permiten confirmar la persistencia de estas prácticas, su reproducción y su constante trasformación. ¿Cómo hacemos entonces para identificar los procesos del racismo en un régimen que se supone cultural y "biológicamente" homogéneo y que tiene solamente en los pueblos indígenas una alteridad social reconocible?

Las investigaciones desarrolladas sobre las poblaciones afromexicanas y mas recientemente los aportes que se han hecho para comprensión del racismo en México han mostrado que es imprescindible atender desde múltiples perspectivas las formas en las que se expresa el racismo "antinegro" teniendo presente que no se trata -tal como lo menciona Cunin (2014)-de un discurso racista institucional explícito sino de la persistencia de una doxa en la que las personas afrodescndientes enfrentan constantemente prejuicios y estereotipos discriminatorios.

La atención a chistes, bromas y frases coloquiales es un primer acercamiento a algunas de las concepciones que socialmente se tienen sobre las personas "negras" y que contribuyen a perpetuar estereotipos y estigmas hacia estas poblaciones, por ejemplo, es frecuente decir "trabajar como negro" en lugar de decir trabajar mucho o de manera extenuante. Esta frase coloquial expresa la asociación mecánica de las personas afrodescendientes con el sometimiento a las largas jornadas de trabajo características de la esclavización. Cabe recordar que uno de los argumentos que se emplearon para justificar la esclavización de personas del África subsahariana fue que su "raza" está mejor dispuesta a las altas temperaturas y los trabajos pesados.

Así mismo, el contenido en los discursos de los medios de comunicación, por ejemplo, nos 
hablan de las concepciones naturalizadas sobre una imaginada condición de "exotismo" y primitivismo de los afrodescendientes. Son notables sobre todo los que provienen de los comentaristas deportivos que sin pudor relatan las proezas de los deportistas de "raza negra" cuando se refieren a lo realizado por un jugador afrodescendiente, mientras que si se trata de un jugador no racializado o racializado como "blanco" o "mestizo" normalmente no tienen raza y tiene nombre, apellido y nacionalidad. O los casos de los programas de "sano entretenimiento" en los que el oprobio puede ser llevado a niveles paroxísticos cuando se emplea el color de piel o las costumbres de las personas como motivos indiscutibles para la burla².

Mejorar la raza, frase que repiten las madres y padres que advierten a sus hijos e hijas casaderos, dan cuenta de la importancia de acceder a otro estatus social saliendo del grupo: aclarando la tez, adquiriendo nuevos capitales culturales, ascendiendo en la clase. Testimonios recogidos durante entrevistas a personas afromexicanas de la Costa de Guerrero y Oaxaca y en la Ciudad de México, dan cuenta de la vigencia de esta noción.

En la sesión de preguntas y respuestas de una conferencia sobre historia de la población afrodescendiente en México, una estudiante de psicología hija de una pareja originaria de la Costa Chica pidió la palabra y relató cómo a lo largo de su experiencia escolar en la Ciudad de México había sido molestada por otros niños por ser "negra", contó de los insultos recibidos y de la constante referencia a su pelo rizado. También refirió que su madre, a petición de la niña agobiada por el acoso, acudió al director de la escuela para que tomara medidas y protegiera a la estudiante. Este en lugar de atender el reclamo de la madre -en tono de superioridad recombino a la mujer- "señora, por favor, ¿es que no se fijó usted con quien se casó?"

Con ello daba a entender que el error era de ella por haber elegido un afrodescendiente como pareja, la madre no debía sorprenderse de que la niña fuera molestada. En este caso las agresiones de los compañeros y el comentario del director aparecen como un castigo justo para esa mujer, el director ejerce una sanción "natural" contra quien no optó por "mejorar la raza", y con ello justifica la mofa de la que es víctima la niña debido a su apariencia. En este hecho aparece "naturalizado" disminuir y violentar a una persona por su tono de piel y su apariencia.

No es imprescindible que existan medidas jurídicas o disposiciones en reglamentos, códigos u otras disposiciones legales -públicas o privadas- para constatar la vigencia de prejuicios, estereotipos e ideas acerca las personas negras. El estigma de la inferioridad que pesa sobre este grupo de población existe y opera. Así pues, estas nociones racializadas y racistas están naturalizadas y hacen parte del sentido común, de las normas aceptadas como las adecuadas u óptimas para la reproducción de la vida social, la doxa es "el sustento irreflexivo de las acciones de los actores en sociedad y [...] funciona de modo sutil a través del lenguaje, a través del cuerpo, a través de las actitudes hacia las cosas, que están por debajo del nivel de la conciencia" (Bourdieu \& Eagleton, 2003, p. 300). Podemos pensar pues, que hay una doxa racista en la que ser negro o afrodescendiente es considerado algo de lo que se debe salir, dejar de ser.

El estudio de la historia de las poblaciones afrodescendientes en México, la observación 
de las interacciones cotidianas, la recopilación de testimonios a través de entrevistas a profundidad permiten afirmar que son por lo menos tres los ejes alrededor de los cuales se articula el racismo hacia la población afromexicana: invisibilización/ocultamiento, exotización/condición de extranjería y la hipervisibilización.Sobre ellos me detengo a continuación.

\section{Invisibilización: herencia decimonónica.}

Al hablar de invisibilidad me refiero a la condición de aquello que no puede ser visto, Nina Friedemann (1992, p. 5) empleó este término para referirse a las comunidades negras en Colombia, para la autora:

\section{la invisibilidad es una estrategia que ignora la actuali- dad, la historia y los derechos de grupos e individuos. Y su ejercicio implica el uso de estereotipos entendidos como reducciones absurdas de la complejidad cultu- ral, que desdibujan peyorativamente la realidad de los grupos así victimizados.}

El concepto, en el caso que atiende Friedemann buscó describir, analizar e incluso denunciar la ignorancia sistemática de las contribuciones de las personas afrodescendientes a la sociedad colombiana, y aunque fue acuñado para explicar la realidad colombiana, su uso se ha generalizado para describir un fenómeno que ocurre en la mayoría de países de América Latina. Así pues, se entiende la invisibilidad como aquello que no es visto y también como aquello que es visto solo de una manera, en el caso de las personas afrodescendientes se ignoran sus contribuciones sociales, económicas y culturales a la construcción de la sociedad y se exacerba la mirada que estereotipa, que disminuye y que por eso mismo oculta y borra.
Estudios históricos y antropológicos han demostrado la significativa participación de personas africanas y afrodescendientes en la conformación de México. A lo largo del periodo virreinal, miles de hombres, mujeres y niños provenientes de diversas regiones de África, arribaron de manera forzada al entonces territorio de la Nueva España para desempeñar tareas en la economía colonial. Su trabajo en minas, haciendas, talleres artesanales, obrajes o quehaceres domésticos, entre otros, produjo riqueza material; sus conocimientos, en convivencia e intercambio con pueblos indígenas, orientales y europeos, construyeron saberes y cultura que dieron lugar heterogeneidad que caracteriza hoy a México (Aguirre, 1946; Velázquez \& Correa, 2004; Velázquez, 2011; Velázquez \& Iturralde, 2012). Así mismo, recientes investigaciones han documentado el lugar que desempeñaron los afrodescendientes en la independencia de México y han arrojado pistas sobre el destino de estas poblaciones una vez abolidas la esclavitud y las distinciones entre los grupos sociales y confirman su presencia y participación en diversas regiones y ocupaciones (Ballesteros, 2010; Díaz Casas, 2015).

No obstante, es justamente en el siglo XIX cuando se empieza a construir la invisibilidad de este grupo de población. En este período los ideales de libertad e igualdad que ayudaron a romper las cadenas de la sujeción y esclavitud a la que habían sido sometidas miles de personas africanas y afrodescendientes también contribuyeron a lo que hoy llamamos invisibilidad de la población afromexicana.

En el caso de México la invisibilización está relacionada inicialmente con la generalización de la idea de que se trata históricamente de un grupo de población numéricamente poco signifi- 
cativo, las observaciones del Baron de Humbolt contribuyeron a forjar y establecer esta idea que pronto sería retomada en las crónicas de viajeros extranjeros conviritiéndose en una verdad poco discutida. Más de un siglo después el antropólogo Gonzalo Aguirre Beltrán (1946) se hizo eco de esta idea afirmando que si bien existió un número importante de personas de origen africano en la Nueva España, este se había reducido, concentrándose apenas en algunas regiones costeras y que acabaría por desaparecer debido a su asimilación biológica y cultural en el mestizaje. Además, posteriormente el mismo autor afirmaría que una de las razones de esta asimilación y desaparición está relacionada con el hecho de que la sociedad postindependiente fue democrática y en ella todos los ciudadanos tenían iguales derechos, lealtades y obligaciones, independientemente de su origen racial o su filiación étnica (Aguirre, 1972).

Un segundo elemento constitutivo de la invisibilización tiene que ver con la concepción que se ha desarrollado sobre la cultura propia de los pueblos y personas afrodescendientes. Hasta que Mintz y Price (2012) con su propuesta metodológica para estudiar y comprender el nacimiento de culturas afroamericanas, eran fundamentalmente dos las comprensiones que sobre esto se habían desarrollado. Por una parte, se afirmaba que las expresiones culturales de la población afroamericana estaban conformadas por la herencia africana y era precisamente la huella de estos legados lo que explicaba su particularidad; y por otra parte, una segunda comprensión que consideraba que las personas africanas introducidas en condición de esclavización -sobre todo al territorio de los Estados Unidos- no se asimilaron nunca y que sus expresiones culturales resultan de las condiciones de opresión y exclusión.
La impronta del relativismo culturalista ha sido muy importante en el desarrollo de los estudios afroamericanos, incluso hoy cuando de manera generalizada se afirma que la cultura es dinámica y su producción es contextual, siguen haciéndose esfuerzos significativos por identificar, entre pueblos y comunidades afrodescendientes, las huellas del legado africano que las constituya como auténticas culturas particulares, identificables y verdaderamente existentes. Como se ha mencionado, la población afrodescendiente en México tempranamente vivió procesos de intensos intercambios socio culturales con los otros grupos de población, resultando, como lo afirman Mintz y Price (2012), en nuevas culturas cuyas expresiones responden a tiempos y espacios específicos, en las que se han combinado discretamente bagajes ancestrales africanos, experincias y saberes de los diversos pueblos originarios de México y otros elementos arribados de la mano de las poblaciones europeas.

La terca necesidad de definir a los grupos sociales en función de un catálogo preciso y bien identificable de rasgos culturales exclusivos, como por ejemplo la posesión y uso de una lengua, unas formas específicas de comer, de vestir, de festejar entre otras y la imposibilidad de identificar y clasificar aquellas que son exclusivamente de origen africano, ha llevado a considerar que las afrodescendientes son poblaciones "aculturadas". No es una consideración menor si tenemos en cuenta que la producción y definición de la alteridad indígena -en México alteridad social por antonomasiase ha hecho a lo largo de la historia a partir de evidenciar su singularidad cultural, ya sea para denostarla o para exaltarla. En la actualidad ser hablante de una lengua originaria sigue siendo criterio primordial de identificación de bene- 
ficiarios de los programas de atención a los pueblos indígenas, los pueblos y comunidades afromexicanas -que en su mayoría comparten espacio y condiciones sociales con los pueblos indígenas- no pueden acceder a este tipo de recursos pues no poseen una lengua propia. Realidad, que además, es vivida por las organizaciones como un acto de discriminación por parte de las instituciones.

Los dos elementos anteriores derivan en un tercer elemento de la invisibilización. Las personas afrodescendientes y sus aportes fueron excluidos de la participación histórica en el mestizaje. Si bien se asume que es un grupo que se ha asimilado al conjunto de la sociedad, en los discursos sobre el mestizo como sujeto nacional y del mestizaje como ideología de la identidad nacional -resultado virtuoso de la combinación del pasado prehispánico y la cultura europea- sus presencia y contribuciones son apenas mencionadas para congratularse de su muy pronta desaparición. Así pues, las personas de origen africano y sus descendientes se han quedado fuera del relato de la nación. Por ejemplo, la escritura y sobre todo la enseñanza de la historia patria generalmente omite hacer mención del arribo de personas provenientes de África en el período colonial, de sus contribuciones sociales y económicas y menos aun de su participación en la gestas independentistas. Si se llega a hacer mención, por ejemplo en los libros de texto de la fromación básica, esta solo hace referencia a la condición de esclavización, asocia África y a las personas africanas y afrodescendientes con la prehistoria, el "salvajismo" y el "atraso" (Masferrer, 2014).
La dinámica que se ha construido entre ocultar y negar - no ver- y la de ver o señalar los estereotipos y estigmas, ha llevado a establecer la idea generalizada de la inexistencia de poblaciones afrodescendientes en México, convirtiéndolas en un cuerpo social excluido de la concepción pluricultural de la nación. Esto, en un régimen como el actual en el que la garantía de derechos y atención social está cada vez más focalizada, ha tenido efectos negativos sobre la garantía de los derechos de los pueblos y comunidades afromexicanas.

\section{Extranjeros, cubanos, nunca mexicanos}

Exotizar, hacer del otro algo exótico, como señala el Diccionario de la RAE (2001, p. 1019) "extranjero o procedente de un país o lugar lejanos y percibidos como muy distintos del propio. [También] extraño, chocante, extravagante". Tras la invisibilización a la que he hecho referencia, hacer de los afrodescendientes un grupo de población extranjero y lejano del ser mexicano, es otra de las formas en las que se expresa el racismo hacia los afrodescendientes. Esto está relacionado con la manera en cómo ha sido concebida la presencia de poblaciones afrodescendientes desde el siglo XIX y sobre todo en el siglo $\mathrm{XX}$.

Una vez construida la idea de la desaparición o dilución de este grupo de población, el pensamiento social, la literatura y posteriormente la industria cultural -el cine de oro y el cine de rumberas y la promoción de la música cubanacontribuyeron a la creación de estereotipo que asocia a las personas negras con un origen extranjero. 
Desde entonces las y los afrodescendientes son cubanos, centroamericanos o caribeños. Son músicos, deportistas o delincuentes siempre llegados de fuera. Análisis recientes sobre la literatura costumbrista de finales del siglo XIX en México y trabajos sobre el cine de mediados del siglo XX (Pulido, 2010) dan cuenta, por una parte, de este proceso en el que se refuerza la invisibilización histórica de los afrodescendientes en México y por otra parte de hipervisibilización y exotización de este grupo social. En el caso del cine y otros productos de la industria cultural de esa época, los hombres y mujeres afrodescendientes o "negros", son considerados extranjeros.

Así, con dificultad se concibe que un afrodescendiente pueda ser mexicano. Datos recogidos en diversas incursiones etnográficas en la Costa Chica, de Guerrero y Oaxaca, así como testimonios de personas afromexicanas en distintos contextos dan cuenta de los efectos que este imaginario tiene sobre la vida concreta de las personas. Por ejemplo, un joven afromexicano, estudiante del nivel medio superior en Cuajinicuilapa, durante un taller sobre historia afromexicana y reconocimiento constitucional relató que en varias ocasiones que ha viajado hacia Acapulco, agentes migratorios en sus inspecciones al transporte lo obligan a identificarse, y al no creerle que se trata de una persona de nacionalidad mexicana lo obligan a descender del autobús y cantar el himno nacional ${ }^{3 .}$

El ejemplo anterior podría tomarse apenas como una anécdota, debido a la ignorancia o desconocimiento individual, en este caso del agente migratorio de turno. Sin embargo, los testimonios de casos como este se repiten, y no solo dan cuenta de sucesos en retenes en esta zona de altos flujos de migración indocumen- tada sino en los puestos de migración de los aeropuertos. Esto también ocurre en el acceso a los servicios públicos, en los que la nacionalidad mexicana de las personas afrodescendientes es puesta en cuestión aun cuando sea comprobada con documentos oficiales. Parece entonces que asistimos a una práctica frecuente, que aun cuando no está fundada en disposiciones jurídicas, sí expresa comportamientos estructurales, no solo en las interacciones individuales sino en los comportamientos institucionales.

La alterización de "lo afro" en México, pasa entonces, de la negación al extrañamiento. De no ver y negar su existencia a convertirla en un elemento externo y peligroso. Tal como lo menciona Saade (2009) hasta bien finales de la década de 1930 se pueden documentar acciones de política migratoria orientadas a desalentar e impedir la migración de personas afroamericanas, argumentando la dificultad que tendrían para integrarse al mestizaje y lo muy nocivo de su influencia en los procesos de integración de los indígenas a la sociedad nacional que en ese momento se llevaban adelante con gran vigor.

La extranjerización de lo afro no es menor, sobre todo al tener en mente que, otro de los discursos y prácticas de la exclusión sobre las que se ha construido la nacionalidad mexicana, es una particular tensión entre la xenofilia y la xenofobia, fenómenos estos en los que la noción de raza juega un papel crítico en la construcción de pertenencia-exclusión de uno u otro grupo. Invisibilización y la exotización en tanto extranjerización son dos características que van de la mano en las modalidades de comprender lo afrodescendiente en México y que marcan las relaciones macro y microsociales con ella. 


\section{Lo que se ve demasiado}

Un tercer elemento que caracteriza esta relación es aquello que se denomina hipervisibilización y hace referencia a aquello que es estereotipado y exacerbado. Aunque parezca una paradoja, a la vez que se ha invisibilizado socialmente las contribuciones de las personas afromexicanas, los estereotipos "raciales" que sobre ellas se han desarrollado históricamente son con frecuencia hipervisibilizados. Algunos autores emplean esta formulación paradójica para explicar otros fenómenos, por ejemplo Manuel Delgado (2015), la utiliza para hablar de la situación de las mujeres en el espacio público, quienes a la vez que no son vistas como actores sociales en el espacio público experimentan en la calle la violencia de la mirada machista sobre lo que se codicia. Invisibilidad y violencia simbólica de una mirada exacerbada.

A la vez que se han desconocido los aportes históricos de las personas afrodescendientes y la diversidad de experiencias que supuso su participación en la sociedad colonial, que se borraron y extranjerizaron en el siglo XIX; en la actualidad los estereotipos -rasgos considerados esenciales y fijos- y estigmas que han pesado sobre las personas "negras" son exaltadas y señaladas.

Philomena Essed (1991) hace una propuesta teórico-metodológica para comprender el racismo en la dimensión micro social de su reproducción, en ella el racismo puede definirse como un proceso en el cual las nociones racistas socializadas se incorporan a significados que vuelven las prácticas inmediatamente definibles y manejables, es decir, que los sujetos son capaces de reconocer y gestionar el significado racista de las prácticas cotidianas pues han estado "familiarizados" con estos significados. Además estas prácticas con implicaciones racistas se vuelven en sí mismas familiares y repetitivas, y las relaciones "raciales y étnicas" subyacentes, o sí se me permite "racializadas y etnizadas", se materializan y se refuerzan a través de estas prácticas rutinarias o familiares en las situaciones de la vida cotidiana.

Rasgos adjudicados a las personas "negras" desde el siglo XVIII y magnificados por los discursos racistas decimonónicos, hoy siguen teniendo vigencia. Considerar que las personas afrodescendientes tienen una disposición "natural" para trabajar en climas cálidos, que prefieren el relajo a la vida ordenada, que la música y el ritmo "vienen en la sangre" son solo algunas de estas consideraciones.

Esto es claro en algunos ejemplos recuperados de entrevistas a mujeres afromexicanas, líderes de organizaciones sociales, quienes al reconstruir sus trayectorias políticas hacen referencia a eventos que identifican como racistas y a los que de alguna manera les atribuyen significatividad en sus procesos personales, han servido para comprender esta otra dimensión del racismo hacia las personas afromexicanas.

Relatan, por ejemplo, que con frecuencia, personas que conocen y desconocidas las apelan Ilamándolas con sobrenombres relacionados con su apariencia: "more", "morenaza", "la mamá de Memín"4. El apelativo a la apariencia tiene su correlato con las concepciones sobre el cuerpo y la sexualidad atribuidas a las mujeres negras, de quienes se piensa están más dispuestas al erotismo y la fogosidad sexual que a mujeres racializadas como blancas o mestizas. En los imaginarios sexuales se asocian los atributos físicos a 
unas ciertas "competencias" sexuales y sobre todo a la falta de constricciones morales. De esto dan cuenta también reclamos publicitarios que explotan la imagen cosificada de hombres y mujeres afrodescendientes.

Otro estereotipo que existe sobre hombres y mujeres afrodescendientes es su mayor fuerza y resistencia. En más de una ocasión mujeres afromexicanas de la Costa Chica de Oaxaca han afirmado que los médicos de los servicios públicos de salud postergan la atención a las parturientas afromexicanas aduciendo que "las negras aguantan más" y dan prioridad de atención a otras mujeres. Representaciones visuales, letras de canciones y otro tipo de referentes proponen normalmente dos miradas sobre la mujer afrodescendiente: la de objeto de deseo o la de madre abnegada, como la representación norteamericana de Aunt Jemime o en el caso de México la que se puede observar en la película de Joselito Rodríguez Angelitos Negros (Pulido, 2010).

Las mujeres entrevistadas a las que he hecho referencia acusan además daños significativos en su autoestima. Califican las experiencias como "frustrantes", "traumatizantes", una de ellas dijo alguna vez "a mí de niña, cuando empecé a ir a la escuela, me pasó una aplanadora, los otros niños se burlaban de mi porque soy negra". Gestos corporales como llevarse las manos hacia el pecho o hacia las sienes mientras cuentan sus experiencias, alzar la voz o por el contrario llorar mientras lo hacen hablan del profundo efecto dañino que estos estereotipos y estigmatizaciones pueden tener sobre las personas.

Cabe señalar que no obstante, estas mujeres que son conscientes de estas experiencias también dejan patente su resiliencia, en sus testimonios consideran que su fuerza transformadora sale justamente de la experimentación de la injusticia y el racismo. Involucradas desde hace algunos años en el movimiento reivindicativo afromexicano desde una perspectiva de lucha por los derechos de las mujeres, han sabido tomar en sus manos la lucha contra el racismo. Han deconstruido los estigmas y estereotipos del racismo y en un complicado proceso de esencialización estratégica, como lo advierte Stuart Hall (2010), una capacidad de revertir las estigmatizaciones y emplearlas "a su favor", por ejemplo, cuando la apariencia -motivo frecuente de estigmatizción- es reivindicada como un articulador identitario: "nosotras las negras estamos aquí" se les escucha decir y continúan " aunque no sepas tu historia, si hay rizo en el pelo, labios gruesos, jahí estamos las afros!".

\section{Obstáculos al reconocimiento constitucional: ¿objeciones del racismo?}

Lo que hoy llamamos genéricamente "movimiento afromexicano" hace referencia a la trayectoria de más de 20 años de construcción de una identidad colectiva de base étnica que articula a organizaciones sociales afrodescendientes sobre todo de la Costa Chica de Guerrero y Oaxaca, acompañadas por otros actores que se han sumado en distintos momentos: académicos, representantes de organizaciones sociales, miembros de partidos políticos y recientemente organizaciones e individuos de otras regiones, como Veracruz y Coahuila, en donde empiezan a gestarse reivindicaciones políticas vinculadas a la autoidentificación como afrodescendientes o afromexicanos. 
Como mencioné en el inicio de este texto, las acciones colectivas de estas organizaciones en los últimos año se han dirigido sobre todo a reclamar su derecho a que el Estado los reconozca jurídicamente y garantice a los pueblos y comunidades afromexicanas, en tanto sujetos colectivos, derechos culturales. Para ello se llevan a cabo diversas actividades. Por ejemplo, reuniones en la región como el Encuentro de Pueblos Negros, que se realiza anualmente desde hace 18 años, espacio en el que se encuentran las comunidades, organizaciones y otros actores cercanos, comparten problemáticas y proyectos, además de reafirmar, a través de la presentación de danza, música y otras expresiones, su patrimonio cultural esgrimido ahora como emblema identitario. También se realizan otro tipo de actividades, como las de cabildeo ante instancias gubernamentales del poder ejecutivo y también del poder legislativo.

En los últimos siete años se han presentado para proceso legislativo varias iniciativas de reforma constitucional para adicionar al artículo 2do de la Constitución, el reconocimiento jurídico de las poblaciones afromexicanas o por lo menos para cambiar leyes reglamentarias y leyes orgánicas de instituciones con el objeto de posibilitar la atención a los pueblos y comunidades afromexicanas. Las iniciativas han sido presentadas por legisladores de distintos partidos políticos y este año incluso se ha elaborado y se está impulsando una iniciativa surgida de la sociedad civil.

Aunque entidades como Oaxaca en 2013, Guerrero en 2014 y la Ciudad de México en 2017 han incluido en sus constituciones y su legislación secundaria el reconocimiento jurídico de este grupo de población, este no se ha logrado en el nivel federal. Además del reclamo de la sociedad civil afromexicana al que se ha hecho referencia, es cada vez más notoria la presión internacional que exige al gobierno mexicano cumplir sus compromisos en esta materia, tal como lo señalan por ejemplo las recomendaciones realizadas por el Comité para la Eliminación de la Discriminación Racial (CERD) a México en 2012. Y no obstante, sigue postergándose este reconocimiento.

Si bien en los últimos años se han realizado algunos esfuerzos importantes por asumir que en México, el racismo es estructurante del modelo de dominación y que su comprensión y combate requieren de desentrañar las sutilezas de su constitución y sus formas de expresión y que también se han logrado algunos avances importantes en la visibilización y valoración social y cultural de las contribuciones de las poblaciones de origen africano, el acompañamiento y registro etnográfico de las acciones emprendidas por las organizaciones afromexicanas, sobre todo de las realizadas frente a autoridades e instituciones del Estado, me permiten afirmar que los obstáculos que enfrenta este reclamo de reconocimiento no se deben solamente a lo que aparece como un desfase de tiempos entre los reclamos sociales y la agenda legislativa.

Desde mi perspectiva, se han esgrimido, además de la falta de presupuesto, la priorización de otros temas en la agenda, dos objeciones que contienen en su seno y reflejan los argumentos antes expuestos entorno de los cuales se ha tejido históricamente el racismo hacia las personas y colectividades afromexicanas. Su invisibilidad que en este caso se traduce en insignificancia en términos demográficos y su condición perpetua de extranjería que en la actualidad subyace a la idea de que no se 
tratan -a diferencia de los pueblos indígenas- de poblaciones originarias de este territorio.

En varias ocasiones, funcionarios de distintos niveles de gobierno y responsabilidad institucional, han argumentado la impertinencia de llevar a cabo acciones de atención a la población afromexicana justificándola en el hecho de que se trata de una población que por una parte goza de los derechos de todos los ciudadanos y que en caso de no ser así se trata de colectividades muy pequeñas y difícilmente identificables.

Este argumento incluso justificó por años, habiendo sido asumida la pluriculturalidad de la nación e instrumentadas algunas estrategias estadísticas de visibilización de la diversidad, el que no se incluyera en los censos y otros instrumentos estadísticos nacionales mecanismos de captación de este grupo de población. Finalmente, tras un largo proceso de negociación entre distintos sectores, en 2015 se incluyó por primera vez en la vida republicana un reactivo para captar autoadscripción afrodescendiente en México. Los datos indican que cerca de 1.4 millones de personas se reconocen negros, afrodescendientes o afromexicanos, es decir cerca del $1.2 \%$ del total de la población se autoadscribe negra, afrodescendiente o afromexicana.

Al margen de la cifra que se obtuvo en este ejercicio o que eventualmente resulte de posteriores ejercicios estadísticos es necesario recordar por una parte las movilizaciones de base étnica en el continente, sean indígenas o afrodecendientes, se ha articulado inicialmente, como lo señala Bengoa (2007), en torno de una demanda de resarcimiento de la dignidad que ha tomado el camino de la lucha jurídica por los derechos como una vía de inclusión a la nación sin renunciar a la singularidad cultural. $Y$ es precisamente esto lo que ha puesto en evidencia el carácter racializado y racista de las naciones en América Latina y México no es una excepción.

Otra de los argumentos que se han esgrimido para oponerse al reconocimiento es la preocupación por la condición de extranjería primigenia de estas poblaciones -en contraste con los pueblos indígenas y su condición de originarios- y la posibilidad de que una vez garantizados derechos en tanto sujetos colectivos a los afromexicanos, otros colectivos "extranjeros" chinos, libaneses, judíos, entre otros- podrían reclamar un trato semejante.

Por una parte, al argumentar esto se pierde de vista que las poblaciones afromexicanas actuales descienden de personas que arribaron al continente en contra de su voluntad, buena parte de ellas establecieron relaciones de convivencia e intercambio con otros grupos sociales durante todo el período novohispano antes de la conformación del estado nación, tal como lo requiere el Convenio 169 de la Organización Internacional del Trabajo (OIT) y cómo lo señala el artículo 2do de la CPEUM para atribuir derechos específicos a los pueblos indígenas. Es importante comprender que el reconocimiento jurídico es además de un gesto simbólico, un primer paso de las medida de igualación frente a los procesos de exclusión a los que dio lugar el establecimiento de los estados nación liberales los que requirieron para su realización "exitosa" la creación de un cuerpo nacional homogéneo y que tuvieron en la noción de raza un dispositivo político de inclusión-exclusión de estos grupos de población. 
Otras colectividades diferenciadas por su origen nacional, su profesión de fe u otro rasgo propio podrían legítimamente reclamar reconocimiento y garantía de derechos específicos en un régimen multiculturalista como el vigente en Canadá. En México, como en la mayor parte de los países de América Latina, se establecieron en la década de los 90 del siglo XX políticas de reconocimiento de la pluriculturalidad o la multietnicidad de la nación, sin embargo, esto no ha significado la transformación del modelo jurídico de garantía de los derechos, sino apenas la modificación de la discursividad del Estado y la remodelación de la atención y asignación de gasto público dirigido a pueblos indígenas y afrodescendientes. El modelo vigente hace inviable, para colectividades que a los ojos de los funcionarios e incluso de científicos sociales aparecen como extranjeras, el reclamo de derechos culturales.

Considero que si bien sería optimo ampliar los márgenes de consideración de la diversidad de la nación incluyendo no solo a indígenas y afrodescendientes sino a otras comunidades, no es pertinente objetar el reconocimiento afrodescendiente haciendo operativo el prejuicio de equiparación de esta colectividad con poblaciones extranjeras. ¿Es imprescindible la condición de pueblo originario para gozar del reconocimiento como sujeto colectivo de derechos? ¿Cuantos siglos de anclaje territorial son necesarios para considerar a un pueblo o comunidad como auténtico componente de la pluralidad cultural de la nación?

Otra de las objeciones a las que se recurre es la supuesta ausencia de rasgos culturales que permitan la definición e identificación de estas colectividades. Con frecuencia se argumenta que esto se debe a que las poblaciones afro- descendientes al ser arrancadas de sus culturas de origen y obligadas primero a convivir con personas de diversos orígenes con quienes no se entendían durante la travesía atlántica y luego a vivir sometidos a la cultura del esclavista, perdieron todos sus referentes culturales y por lo mismo carecen de rasgos que los definen: no tienen una lengua propia, su vestimenta es de origen colonial, y carecen de sistemas de parentesco y de otras normas propias que regulen su vida material y simbólica. Si acaso se reconocen algunos aportes de un abstracto origen africano a expresiones de la creación dancística y musical.

Estos argumentos se han elaborado de la mano del desarrollo de una comprensión cosificada y folclorizada de la etnicidad que ha tendido a reducir esta a la existencia y posesión de un catalogo bien identificable de rasgos culturales exclusivos de una colectividad. Considero que la identificación y definición de las poblaciones y comunidades afromexicanas no debería hacerse pensando en encontrar reservorios o huellas de la cultura africana -si es que pudiéramos hablar de ella en singularni tampoco como recipientes vacíos que aceptaron irreflexivamente las imposiciones de la cultura dominante. Se trata de nuevas formas de organización social surgidas del intercambio -a veces conflictivo y otras veces armoniosocon otros grupos y del desempeño en nuevos contextos económicos, en donde fue necesario recrear y crear nuevas reglas de parentesco, otras formas de hablar, comer, vestir, festejar e interpretar el mundo.

Por lo tanto es pertinente poner en cuestión la visión desarrollada sobre la etnicidad, incluso aquella que está asentada en el supuesto señalado por el Convenio 169 de la OIT y desarro- 
llado por el artículo 2do de la CPEUM (2017, p. 2), el texto constitucional define, para efectos jurídicos, un tipo ideal de comunidad que a la letra dice: "Son comunidades integrantes de un pueblo indígena, aquellas que formen una unidad social, económica y cultural, asentadas en un territorio y que reconocen autoridades propias de acuerdo con sus usos y costumbres". Con ello se ha creado la ficción de la existencia empírica de organizaciones sociales que se ajustan al modelo y cumplen a cabalidad cada uno de estos aspectos, dejando fuera a aquellas que divergen de esta definición ${ }^{5}$.

Argumentadoloanterior, se puedeconstatarque las expresiones del racismo hacia los pueblos y comunidades afromexicanas ciertamente puede identificarse en los pequeños gestos cotidianos inconscientes -en la doxa- que dan cuenta de la capacidad del racismo de implantarse, transformarse y ser una herramienta de perversa efectividad en la estructuración jerarquizada de las sociedades contemporáneas. Discursos que aparentemente carecen de importancia-dichos y chistes- operan como pequeños rituales que le recuerdan a las personas afromexicanas el lugar que ocupan en el orden social racializado. Pero el racismo no solo se produce en estos espacios aparentemente anodinos de la cotidianidad, por el contrario, en donde se reproduce con mayor fuerza es en los discursos y las prácticas de las instituciones del Estado. Prejuicios, estereotipos y estigmas tienen un efecto sobre las posibilidades del pleno ejercicio de derechos de pueblos y comunidades.
Aquí apenas se han esbozado algunos argumentos que deben ser enriquecidos con los aportes que permiten las aproximaciones antropológicas. La caracterización del racismo en México es apenas un campo en formación en el que se están desarrollando nuevas y creativas interpretaciones.

En este marco, el estudio en particular sobre las poblaciones afrodescendientes está siendo abordado, es imprescindible desarrollar investigaciones que atiendan otros espacios y expresiones de la afrodescendencia, no solo en los lugares tradicionales de identificación afro sino en otras regiones del país y sobre todo en las ciudades, espacios de mayor complejidad en donde los regímenes de identificación, pertenencia y exclusión social están en permanente negociación. Así mismo es imperativo ampliar los marcos de comprensión de la diversidad cultural en México, profundizando en los procesos de construcción de las alteridades sociales contemporáneas. $Y$ finalmente es preciso advertir la importancia de que el estudio del racismo hacia las personas afrodescendientes contribuya a disipar prejuicios, estereotipos y estigmas. Puede ocurrir que los estudios que se desarrollan alimenten viejas prácticas racialistas -como el uso de tablas cromáticas de piel para "medir" identidad racial- que lejos de combatir el racismo lo dotan de nuevos sentidos y reviven su operatividad. 


\section{Notas}

${ }^{1}$ En 2015 se formó con financiamiento de CONACyT la Red de Investigación Interdisciplinarios Identidad, Racismo y Xenofobia (Red Integra), de la que hacen parte más de 100 investigadores de distintas instituciones públicas en México y cuyo objetivo es desarrollar nuevas perspectivas de investigación interdisciplinaria sobre el racismo considerando que se trata de un fenómeno multicausal y se expresa en distintas esferas de los social.

${ }^{2}$ Por ejemplo, en 2010 a propósito de la celebración del campeonato mundial de futbol en Sudáfrica las televisoras más importantes del país introdujeron pequeños sketches "cómicos" en los que se reproducían- supuestamente- algunas de las características de los pobladores nativos de ese país: actores maquillados de negro a la manera del blackface, vestidos apenas con unas pieles de animales salvajes y tocados con huesos en la cabeza, hablando borucas, eran el marco y el motivo para un sinnúmero de bromas a propósito del color de piel, del estado de atraso y salvajismo comparado con el mexicano, sobre la fogosidad de las mujeres, etcétera. La denuncia del racismo contenido en estos programas recibió como réplica por parte de Televisa, que ellos no consideraban que allí hubiera ningún contenido racista, se trataba- según ellos- de "sano entretenimiento".

${ }^{3}$ La Costa Chica es una región ubicada en la franja costera del pacífico sur, región que hace parte de uno de los corredores por donde personas migrantes indocumentadas pasan en su tránsito hacia el norte del continente. Son frecuentes a lo largo de esta y otras regiones los retenes o puestos de control migratorio.

${ }^{4}$ En 2005 se desató una polémica muy importante alrededor de unas declaraciones del entonces presidente Vicente Fox quien

\section{Referencias bibliográficas}

Aguirre, B. (1946). La población negra de México, 1519-1810: estudio etno-histórico. México: Ediciones Fuente Cultural. (2da Ed.) (1972). La población negra de México: estudio etnohistórico. México: Fonde de Cultura Económica.

Ballesteros, D. (2010). De castas y esclavos a ciudadanos. Las representaciones visuales del México independiente. (Tesis inédita de Maestría en Historia Moderna y Contemporánea, Instituto de Investigaciones Dr. José María Luis Mora) México.

Bengoa, J. (2007). La emergencia indígena en América Latina. USA. Santiago de Chile: Fondo de Cultura Económica.

Bourdieu, P. \& Eagleton, T. (2003). Doxa y vida cotidiana: una entrevista. En Zizek, S. (comp) Ideología: un mapa de la cuestión (pp. 295-309). Madrid: Fondo de Cultura Económica.

Campos, I. (2009). Estigma y antichinismo: violencia e identidad nacional en el México revolucionario. En Barceló, R. (Coord), Extraños en tierra ajena. Migración, alteridad e identidad México (pp. 159-183). México: Plaza y Valdés.

Carroll, P. (2001). Blacks in Colonial Veracruz. Austin: University of Texas Press. afirmó -en un contexto de particular tensionen en torno de las medidas antiinmigrantes impulsadas por los Estados Unidos- que los inmigrantes mexicanos en EUA hacen el trabajo que ni los negros quieres hacer. Una vez tomadas las medidas diplomáticas para resolver el desaguisado, en México se publicaron unos sellos postales conmemorativos con la imagen de "Memín Pinguín", personaje central de un comic popular de la década de 1940 en México. El comic relata las andanzas de un niño "negro" retratado con rasgos exagerados, los labios muy gruesos y orejas de soplillo, que ayuda a su madre vendiendo periódicos y limpiando zapatos. Sus travesuras y un cierto aire torpe e inocente son motivo de burla de los otros niños no "negros". La madre de Memín es también retratada de forma exagerada. Este acto conmemorativo fue leído en Estados Unidos como una nueva provocación de lo que consideraron el no asumido racismo mexicano. En México este incidente desató también una importante reflexión en torno de la identidad nacional, las concepciones sobre la raza y el racismo en México, fenómeno negado pero persistente, y sobre todo puso sobre la mesa la necesidad de reflexionar sobre el amplio espectro de problemáticas en torno de migración y racismo ente EUA y México (Lomnitz, 2005).

${ }^{5}$ Como siempre en las disposiciones jurídicas, en el artículo $2^{\text {do }}$ hay resquicios que permiten ampliar el reconocimiento. El último párrafo considera la posibilidad de garantizar los derechos ahí consagrados a las "comunidades equiparables". No se han definido esas comunidades y tampoco se ha recurrido a esta figura para efectivamente eludir los obstáculos que se han interpuesto al reconocimiento constitucional de pueblos y comunidades afromexicanas.
(2011). El debate académico sobre los significados sociales entre clase y raza en el México del siglo XVIII. En Velásquez, M. (2011). Debates Históricos Contemporáneos: Africanos y Afrodescendientes en México y Centroamérica (pp. 111-142). México: INAH/ UNAM/ CEMCA.

Castellanos, A. (2000). Racismo, multietnicidad y democracia en América Latina. Nueva Antropología, XVII(58), 9-25. (2001). Notas para estudiar el racismo hacia los indios de México. Papeles de Población, 7(28), 165-179.

_ (2003). Imágenes del racismo en México, México: Plaza y Valdés.

Constitución Política De Los Estados Unidos Mexicanos, Constitución publicada en el Diario Oficial de la Federación el 5 de febrero de 1917, TEXTO VIGENTE, Última reforma publicada DOF 2402 2017. Recuperado de: http://www.diputados.gob.mx/ LeyesBiblio/pdf/1_240217.pdf

Correa, C. (2013). Procesos de socialización familiar y relaciones raciales en El Ciruelo (Tesis inédita de maestría en Antropología Social, CIESAS.). México. 
Cunin, E. (2014). Administrar los extranjeros: raza, mestizaje, nación: migraciones afrobeliceñas en el territorio de Quintana Roo, 1902-1940. México: CIESAS; IRD; Karthala.

Delgado, M. (2015). La hipervisibilización de las mujeres en el espacio urbano, el cor de les aparences. Bloc de Manuel Delgado. Recuperado de: http://manueldelgadoruiz.blogspot.mx/2015/05/ la-hipervisibilizacion-de-las-mujeres.html

Díaz, C. (2015). ¿De esclavos a ciudadanos? Matices sobre la "integración" y "asimilación" de la población de origen africano en la sociedad nacional mexicana, 1810-1850. En De la Serna, J. (coord.). Negros y morenos en Iberoamérica. Adaptación y conflicto. México: Universidad Nacional Autónoma de México.

Essed, Ph. (1991). Understanding Everyday Racism: An Interdisciplinary Theory. EUA, SAGE.

Friedemann, N. (1992). De negros en Colombia: identidad e invisibilidad. América Negra. (3), 25-35.

Gall, O. (Coordinadora) (2007). Racismo, mestizaje y modernidad: visiones desde latitudes diversas, México: CEIICH y CRIM-UNAM (2014). Interseccionalidad e interdisciplina para entender y combatir el racismo. Revista Interdisciplina, 2(4), 9-34.

Gómez, J. (coord) (2005). Los caminos del racismo en México. México: Plaza y Janés.

(1991). El movimiento antichino en México (1871-1934).

Problemas del racismo y del nacionalismo durante la Revolución Mexicana. México: INAH.

Good, C. (1998). Reflexiones sobre las razas y el racismo; el problema de los negros, indios, el nacionalismo y la modernidad. Dimensión Antropológica, 14, 109-131. Recuperado de: http://www. dimensionantropologica.inah.gob. $\mathrm{mx} / \mathrm{p} \mathrm{p}=1290$

Hall, S. (2010). Sin garantías: trayectorias y problemáticas en estudios culturales. Restrepo, E., Walsh, C. \& Vich, V. (Eds.). Bogotá: Instituto de Estudios Sociales y Culturales Pensar, Universidad Javeriana Instituto de Estudios Peruanos Universidad Andina Simón Bolívar, sede Ecuador Envión Editores

Iturriaga, E. (2016). Las élites de la ciudad blanca. Discursos racistas sobre la otredad. México: UNAM.

Jiménez, R. (2004). La construcción de las ideas sobre la raza en algunos pensadores mexicanos de la segunda mitad del siglo XIX. Revista Secuencia, (59), 71-100.

Knight, A. (2004). Racismo, revolución e indigenismo: México, 1910-1940, Puebla: Benemérita Universidad Autónoma de Puebla.

Lomnitz, C. (1995). Las salidas del laberinto: cultura e ideología en el espacio nacional mexicano. México: J. Moritz

(2005). Mexico's Race Problem And the real story behind

Fox's faux pas Boston Review, 30(6), 18.

McCaa, R. \& Stuart, S. et al. (1979). Race and Class in Colonial Latín America: A Critique, Comparative Studies in Society and History, XL(3), 421-433.

Masferrer, C. (2014). Racismo, ignorancia y olvido. La esclavitud y las personas de origen africano en la educación primaria y secundaria de México. En Serna, J. \& Cruz, F. (coords.), Afroindoamérica. Resistencia, visibilidad y respeto a la diferencia, México: UNAM, CIALC.
(2016). Yo no me siento contigo. Educación y racismo en pueblos afromexicanos. Diálogos sobre Educación, 7(13), 1-17.

Mintz, S. \& Price, R. (2012). El origen de la cultura africanoamericana. Una perspectiva antropológica, México: CIESAS, UAM, UIA.

Moreno, M. (2008a). Historically Rooted Transnationalism: Slightedness and the Experience of Racism in Mexican Families. Journal of Intercultural Studies, 29(3), 283-297.

(2008b) . Looking Emotionally: Photography, Racism and

Intimacy in Research. History of the Human Sciences, 21(4), 66- 83. (2010). Distributed Intensities: Whiteness, Mestizaje and the Logics of Mexican Racism, Ethnicities, 10, 387-401.

Navarrete, F. (2016). México racista: una denuncia. México: Planeta.

Palmer, C. (1976). Slaves qf the White God, Cambridge: Harvard University Press.

Pulido, G. (2010). Mulatas y negros cubanos en la escena mexicana, 1920-1950, México: Instituto Nacional de Antropología e Historia.

Quecha, C. (2016). Familia, infancia y migración: un análisis antropológico en la Costa Chica de Oaxaca. México: UNAM.

Real Academia de la Lengua (2001). Diccionario de la Lengua Española. Madrid: Real Academia de la Lengua.

Saade, M. (2009). Una raza prohibida: afroestadounidenses en México. En Yankelevich, P. (Coord.) Nación y extranjería. La exclusión racial en las políticas migratorias de Argentina, Brasil, Cuba y México (pp. 231-276). México: Programa Universitario México Nación

Stern, P. (1994). Gente de color quebrado: Africans and Afromestizos in Colonial Mexico, Colonial Latin American Historical Review, III(2), 185-205.

Sue, C. (2013). A Land of the Cosmic Race: Race Mixture, Racism, and Blackness in Mexico. Oxford University Press.

Taguieff, P. (2010). Introducción al libro "El color y la sangre". Doctrinas racistas a la francesa. En Hoffmann, O. \& Quintero, O. (coord.), Estudiar el racismo. Textos y herramientas . Documento de Trabajo No. 8 / Document de Travail No. 8, México: Proyecto AFRODESC / EURESCL.

Telles, E. (2014). Pigmentocracies. Ethnicity, Race and Color in Latin America, Chapel Hill: University of California, Press.

Urías, B. (2007). Historias secretas del racismo en México (19201950). México: Tusquets.

Velázquez, M. \& Iturralde, G. (2012). Afrodescendientes en México: una historia de silencio y discriminación. México: CONAPRED, INAH. (2016). Afromexicanos: reflexiones sobre las dinámicas del reconocimiento. Anales de Antropología. 50(2), 232-246.

Velázquez, M. \& Correa, E. (Comp) (2004). Poblaciones y culturas de origen africano en México. México: INAH.

Velázquez, M. (2011). Africanos y afrodescendientes en México: premisas que obstaculizan entender su pasado y presente. Cuicuilco, 18(51), 11-22.

Vinson III, B. (2001). Bearing Arms for His Majesty, Stanford: Stanford University Press. 